\title{
Muffins isentos de glúten e lactose desenvolvidos com resíduo de polpa de graviola (Annona muricata)
}

\author{
Janyne Ribeiro dos $\operatorname{Santos}^{1}$, Josianny Alves Boêno ${ }^{1}$ \\ ${ }^{1}$ Instituto Federal Goiano - IF Goiano, Campus Morrinhos, Morrinhos, Goiás, Brasil. E-mail: janyne_ribeiro_@hotmail.com, \\ josianny.boeno@ifgoiano.edu.br
}

Recebido: 15/04/2016; Aceito: 07/07/2016.

\section{RESUMO}

Apesar do acréscimo na produção nos últimos anos, atualmente ainda são escassos os produtos no mercado destinados à indivíduos com restrições alimentares. O presente estudo visou desenvolver "muffins" (bolinhos) isentos de glúten e lactose, utilizando farinha de arroz e resíduo da filtragem da polpa de graviola (Annona muricata), e avaliar a influencia do resíduo nas características da massa. Os muffins elaborados com $0 \%$ (padrão), 10, 20 e $30 \%$ de resíduo da polpa de graviola em substituição a farinha de arroz, foram submetidos a análises físicas de peso, diâmetro e espessura antes e depois do forneamento, cálculo da expansão de massa, análise de $\mathrm{pH}$, cinzas e umidade. Valores obtidos nas análises físicas dos muffins demostraram que as amostras com maior adição do resíduo (30\%), obtiveram maior diâmetro, crescimento da massa (espessura), e coloração mais escura. Os valores de pH e umidade para o muffin também variaram em relação à concentração do resíduo, e os valores para cinzas não demonstraram diferença significativa em relação à adição. A partir dos resultados obtidos foi possível observar que o aumento nos níveis de adição de resíduo de polpa de graviola influenciou as características da massa dos muffins desenvolvidos.

Palavras-chave: substituição, análises, massa, características.

\section{Development of muffins gluten and lactose-free with soursop (Annona muricata) pulp residue}

\begin{abstract}
Despite the increase in production in recent years, currently still are scarce products on the market destined to individuals with dietary restrictions. This study aimed to develop "muffins" gluten and lactose free, using rice flour and residue from the filtering of soursop (Annona muricata) pulp, and evaluate the influence of residue in the mass characteristics. Muffins made with 0\% (default), 10, 20 and 30\% residue of soursop pulp replacing rice flour, were submitted to physical analysis of weight, diameter and thickness before and after from baking, calculation of expansion mass, $\mathrm{pH}$ analysis, ashes and humidity. Values obtained in the physical analyzes of muffins demonstrated that samples with higher addition of the residue $(30 \%)$, obtained larger diameter, mass growth (thickness) and a darker coloration. The $\mathrm{pH}$ and humidity values for the muffin also varied in response to the concentration of the residue, and the values for ashes showed no significant difference with respect to addition. From the results it was observed that the increase in the levels of addition of soursop pulp residue influenced the mass characteristics of developed muffins.
\end{abstract}

Key words: replacement, analysis, mass, characteristics. 


\section{Introdução}

As alergias e intolerâncias relacionadas ao consumo de alimentos têm se mostrado cada vez mais preocupantes devido ao aumento constante de casos no decorrer dos anos. Pode-se dizer que a ingestão de alimentos ou aditivos alimentares podem ocasionar várias reações adversas no organismo em alguns indivíduos (SOLÉ et al., 2008). Um indivíduo, durante sua a vida, ingere grandes quantidades de alimentos com alta carga proteica e sabe-se que, as alergias ou intolerâncias, são geralmente causadas por proteínas, podendo-se citar como principais proteínas responsáveis pela maioria dos casos de alergia alimentar as proteínas contidas em alimentos como: o leite de vaca, o trigo, o amendoim, a soja, os frutos do mar e as nozes (PEREIRA et al; 2008).

O leite está entre os principais responsáveis pela maioria dos casos de alergia alimentar. Componentes, como as proteínas e a lactose presente no leite também constituem outra importante fonte causadora de reações adversas a alimentos para alguns indivíduos. Em grande parte dos mamíferos a atividade da enzima lactase tende a diminuir naturalmente com o passar do tempo (MATTAR; MAZO, 2010). Porém alguns indivíduos podem nascer com uma deficiência na produção de lactase, açúcar do leite. Esta deficiência conduz à má digestão da lactose, o que começa a caracterizar intolerância à mesma na forma de sintomas gastroenterológicos (TÉO, 2002).

Assim como o leite, o glúten também pode causar uma reação adversa no organismo de muitos indivíduos. Primeiramente pode-se definir o termo glúten como uma porção proteica formada por glutenina e gliadina, (proteína da classe das prolaminas), após hidratação. Geralmente estas proteínas são encontradas no trigo principalmente, bem como na aveia, no centeio, na cevada, no malte, e em vários cereais em geral. Em indivíduos predispostos geneticamente, a permanente intolerância à gliadina causa a doença celíaca (DC), que é a indisposição ao glúten (CÉSAR et al., 2006).

Atualmente, apenas um tipo de tratamento para a doença celíaca é disponível: o tratamento dietético com remoção de glúten (MAURÍCIO et al., 2012). Porém, a prática do consumo de uma dieta isenta de glúten não se constitui uma tarefa de fácil execução, pois habitualmente as pessoas consomem massas como pães, bolos, biscoitos, pizzas, macarrão que são comumente preparados com farinha de trigo (LÓPEZ et al., 2004).

Nesses tipos de produtos panificáveis, a adição de resíduos de frutas ou substituição de outros ingredientes por resíduos tem sido constante alvo de estudo, devido ao seu caráter econômico, ambiental e nutricional. Segundo Lima et al. (2011), as indústrias de alimentos têm investido constantemente no aumento de sua capacidade produtiva, por isso, acabam gerando grandes quantidades de resíduos agroindustriais ou subprodutos, que geralmente são considerados como custo operacional para a indústrias ou apenas fonte de contaminação no meio ambiente. Como a quantidade de resíduos pode atingir muitas toneladas, agregar valor a ele é uma solução tanto econômica quanto ambiental. Entretanto a forma de reaproveitamento requer uma investigação científica e tecnológica.

Indústrias de processamento de produtos de frutas, como sucos, néctares, geleias, entre outros, tendem a gerar muitos resíduos, visto que geralmente apenas a polpa ou o sumo é aproveitado. O Brasil é um país rico em frutas, tanto em quantidade produzida, quanto em variedade. Nos últimos anos as frutas têm apresentado importância crescente no país, no mercado interno bem como no internacional. Em 2014, o valor das exportações de frutas frescas foi de U\$ 877,6 milhões, e a quantidade exportada foi de 778 mil toneladas (GARIB, 2015). De acordo com levantamento do Instituto Brasileiro de Geografia e Estatística (IBGE), a produção brasileira de frutas em 2013, somou 41,6 milhões de toneladas (REETZ et al., 2015).

No Brasil algumas frutas ainda são pouco valorizadas e bem menos reconhecidas que outras frutas mais comuns. A família das Anonáceas é composta por cerca de 119 gêneros e mais de 2000 espécies, na qual está incluída a graviola (Annona muricata L.), sendo seu cultivo recente e de grande relevância socioeconômica nos países que possuem produção comercial por meio da geração de emprego e renda. Vêm, recentemente, ganhando importância no mercado mundial, dada sua condição de fruta exótica e pela sua qualidade, dentre as quais o valor nutracêutico (vitaminas, antioxidantes e outras propriedades funcionais) (SÃO JOSÉ et al; 2014). A graviola é considerada, ainda uma das importantes frutíferas cultivadas no Nordeste Brasileiro, principalmente nos Estados da Paraíba, Ceará, Pernambuco e Bahia, sendo seus frutos utilizados na fabricação dos mais variados produtos (SACRAMENTO, 2003). É uma fruta apreciada por seu aroma e sabor característicos (SANTOS et al., 2014). Em nosso país, a crescente demanda e o interesse pela polpa de graviola, tanto pelos consumidores como pelas indústrias de sucos, sorvetes e doces, justificam sua inclusão no rol das frutas tropicais brasileiras de maior aceitação sensorial (OLIVEIRA, 2001).

Dentre os produtos mais usados para adição ou substituição de ingredientes, o bolo é um produto que ganha cada vez mais importância em relação ao consumo no Brasil (MAURÍCIO et al., 2012). Segundo os dados mais recentes da Associação Brasileira das Indústrias de Biscoitos, Massas Alimentícias e Pães e Bolos Industrializados (2015), no ano de 2014 o setor de bolos industrializados faturou cerca de 685 milhões de reais. Como mencionado por Borges et al. (2010), 
grande parte dos produtos de panificação é composta por ingredientes que desempenham funções específicas no processo de formação da massa. Em vista disto, tevese como objetivo neste estudo desenvolver muffins isentos de glúten e lactose, utilizando farinha de arroz e resíduo da polpa de graviola, e avaliar se a adição do resíduo da polpa de graviola influencia as características da massa através de análises físicas e químicas.

\section{Material e Métodos}

O estudo foi conduzido no Instituto Federal Goiano, Campus Morrinhos, no laboratório de Química onde foram conduzidas as análises na polpa de graviola; laboratório de panificação, onde foram realizados os testes de formulação até a obtenção final dos muffins.

Com exceção da graviola, os ingredientes: farinha de arroz, Açúcar cristal, óleo de soja vegetal, fermento em pó químico, e ovo, foram adquiridos no comércio local do município de Morrinhos, GO, sendo todos rotineiramente utilizados em culinária. Foram feitos testes preliminares variando as concentrações de resíduo de graviola, até a formulação obtida. As porcentagens de substituição pelo resíduo foram consideradas em relação à proporção total de farinha de arroz.

A formulação de muffin padrão foi preparada de acordo com Martínez-Cervera et al. (2012) com algumas modificações: bateu-se as claras (30 g) por 5 minutos, em batedeira, na velocidade máxima; acrescentou-se o açúcar ( $80 \mathrm{~g})$ e bateu-se por 1 minuto, na velocidade máxima. Adicionaram-se a gema (55 g) e metade do leite $(25 \mathrm{~g})$ e bateu-se por 1 minuto, na velocidade 3 . Na velocidade 4 adicionaram-se o restante do leite ( $25 \mathrm{~g}$ ) e o óleo (35 g) (aos poucos) e bateu-se por mais 2 minutos. A farinha $(100 \mathrm{~g})$ foi peneirada e adicionada aos poucos, assim como o fermento $(2 \mathrm{~g})$. $\mathrm{O}$ forno foi pré-aquecido, por 25 minutos a $170{ }^{\circ} \mathrm{C}$.

As quatro formulações desenvolvidas foram submetidas à aplicação de análises químicas e físicas, como cinzas, umidade, $\mathrm{pH}$, peso, diâmetro, espessura, e ainda foi observado a uniformidade da crosta e a porcentagem de volume de crescimento após o forneamento. Os muffins foram produzidos conforme o fluxograma da Figura 1.

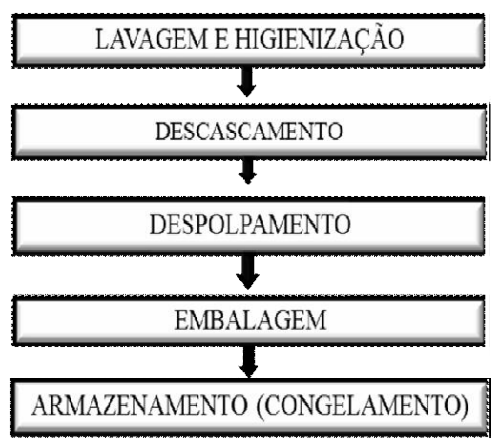

Figura 1. Fluxograma de obtenção da polpa e resíduo da polpa de graviola

A Tabela 1 mostra os tratamentos a que foram submetidas às formulações do muffin desenvolvido com substituição parcial da farinha de arroz por resíduo da polpa de graviola. O fluxograma (Figura 1) mostra as etapas para obtenção do resíduo utilizado nas formulações de muffin elaboradas. Os frutos maduros, provenientes de uma planta (gravioleteira) cultivada sem qualquer tipo de adubação, fertilização ou irrigação, foram adquiridos em uma propriedade residencial do município de Morrinhos - GO.

As graviolas foram colhidas quando atingiram o estado de amadurecimento. Posteriormente foram higienizadas em água corrente e com o auxílio de uma escova para retirar as sujidades, posteriormente, as graviolas foram sanitizadas em água clorada com hipoclorito de sódio a $50 \mathrm{ppm}$ por aproximadamente 10 minutos, devido a sensibilidade da casca fruto maduro, para não ocorrer rompimento da casca. As frutas foram posteriormente descascadas com faca de aço inox, em seguida, parte da polpa de graviola (GP) obtida foi separada para posterior armazenamento. Foi feita a retirada manual das sementes.

Tabela 1: Formulações do muffin padrão e com substituição parcial da farinha de arroz por resíduo da polpa de graviola

\begin{tabular}{lcccc}
\hline Ingredientes & $\mathrm{T} 0(0 \%)$ & $\mathrm{T} 10(10 \%)$ & $\mathrm{T} 20(20 \%)$ & $\mathrm{T} 30(30 \%)^{*}$ \\
\hline Farinha de arroz & 40,6 & 36,54 & 32,48 & 28,42 \\
Resíduo da polpa de graviola (fruta) & 0 & 4,06 & 8,12 & 12,18 \\
Açúcar cristal & 25,9 & 25,9 & 25,9 & 25,9 \\
Ovo & 16,7 & 16,7 & 16,7 & 16,7 \\
Óleo vegetal & 12,9 & 12,9 & 12,9 & 12,9 \\
Fermento em pó químico & 3,7 & 3,7 & 3,7 & 3,7 \\
Sal refinado & 0,2 & 0,2 & 0,2 & 0,2 \\
\hline *Porcentagem de substituição de farinha de arroz por resíduo de polpa da graviola equivalente a $0 \%(\mathrm{~F} 0), 10 \%(\mathrm{~F} 1), 20 \%(\mathrm{~F} 2)$ e $30 \%(\mathrm{~F} 3)$ de $100 \%$ \\
do peso da farinha de arroz.
\end{tabular}


O "resíduo" da polpa de graviola (GR) foi obtido semelhante ao que ocorre para a obtenção de sucos e néctares, com a filtragem da mesma para extração do líquido, sendo que a polpa fibrosa proveniente foi batida, em liquidificador, por cerca de 20 segundos e coada, em peneira plástica de polietileno, para extrair a parte mais líquida. A polpa mais concentrada restante da peneirarem foi novamente batida, sendo assim obtido o "resíduo" (material fibroso) da extração do suco da fruta (Figura 2).

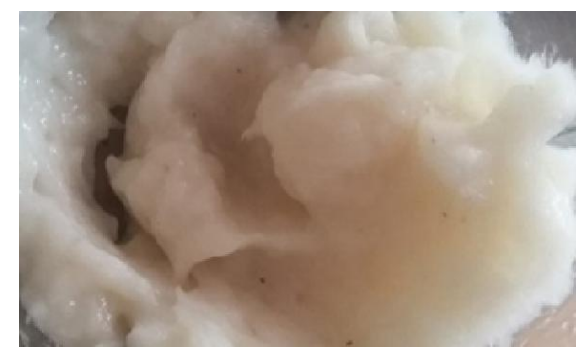

Figura 2. Resíduo obtido da polpa de graviola.

No preparo dos muffins, primeiramente todos os ingredientes (Tabela 1) para todas as formulações foram pesados em balança de precisão, devidamente calibrada. Para a elaboração da massa, as gemas de ovos foram previamente batidas em liquidificador industrial, juntamente com o açúcar e óleo por dois minutos; a mistura proveniente foi novamente batida em batedeira, durante mais três minutos na velocidade máxima. Posteriormente a farinha de arroz, e o sal foram adicionados à mistura sendo batidos por mais cinco minutos. Foi adicionado o resíduo da polpa de graviola e a massa foi novamente batida até obter consistência homogênea, cerca de dois minutos, variando de acordo com a quantidade de resíduo adicionado para cada formulação. Por último bateu-se às claras separadamente por três minutos, na batedeira, na velocidade máxima, sendo adicionadas ao restante da mistura seguida pelo fermento. A massa final foi batida na menor velocidade por mais um minuto.

A massa foi então adicionada em formas de silicone de $3,5 \mathrm{~cm}$ de altura que foram preenchidas por $2 \mathrm{~cm} \mathrm{de}$ massa (Espessura Antes) medidos com paquímetro, com cerca de $50 \mathrm{~g}$, obtendo-se como rendimento 5 muffins em cada uma das formulações. Tabuleiros de metal contendo as formas foram submetidos ao forneamento em Forno Elétrico a $200{ }^{\circ} \mathrm{C}$, durante 25 minutos. Os muffins foram avaliados quanto à algumas de suas propriedades físicas como peso, espessura, diâmetro e uniformidade da crosta. A Figura 3 mostra o fluxograma utilizado na preparação dos muffins elaborados com o resíduo de polpa de graviola.

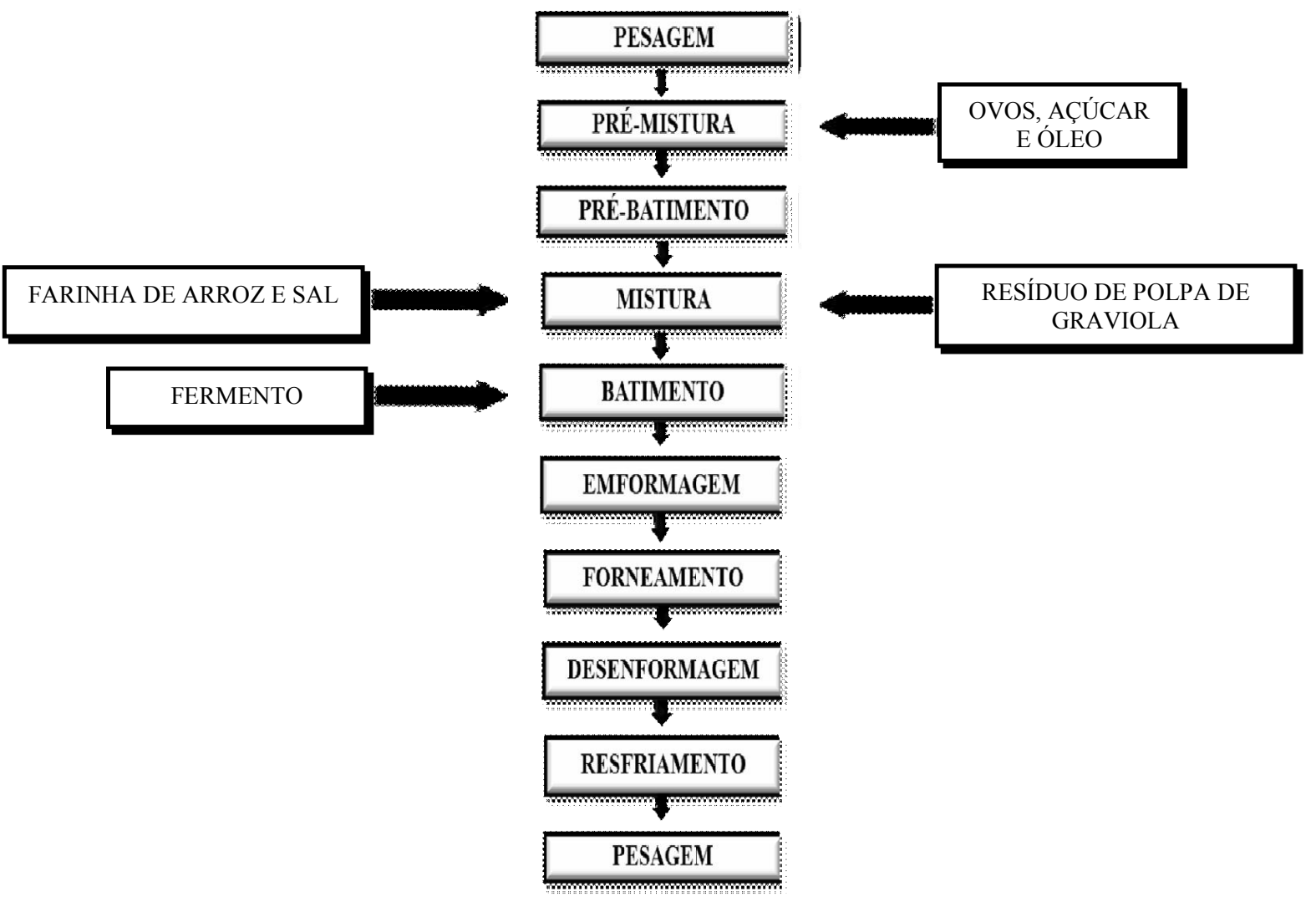

Figura 3. Fluxograma de desenvolvimento dos muffins adicionados de resíduo de polpa de graviola. 
Para a realização das análises na polpa e no resíduo da graviola, as amostras foram descongeladas sob refrigeração por cerca de 2 horas e meia. Posteriormente, os recipientes foram retirados da refrigeração até atingir a temperatura ambiente. Sendo que, após esse procedimento, o resíduo foi homogeneizado em liquidificador.

Para análises de $\mathrm{pH}$, cinzas, umidade e, os bolinhos foram resfriados à temperatura ambiente, e posteriormente homogeneizados/triturados em liquidificador industrial peneirados e armazenados em potes de polietileno transparentes $0,18 \mathrm{~mm}$ de espessura, vedados até o momento das análises.

A medição de $\mathrm{pH}$ das amostras de polpa e resíduo foi realizada em triplicata com medidor de $\mathrm{pH}$, devidamente calibrado (BRASIL/IAL, 2008).

Os sólidos solúveis da polpa e do resíduo foram determinados por refratometria conforme metodologia do Instituto Adolf Lutz Brasil (2008) utilizando-se refratômetro digital portátil previamente calibrado com água destilada. Três gotas da amostra foram gotejadas no prisma do aparelho. A análise foi realizada em triplicata. $\mathrm{O}$ valor de encontrado para ${ }^{\circ}$ Brix foi corrigido em relação à temperatura de medição, de acordo com tabela contida no manual do Instituto Adolf Lutz Brasil (BRASIL/IAL, 2008) na determinação de sólidos solúveis por refratometria para frutas e produtos de frutas.

A acidez titulável foi determinada por volumetria em triplicata, sendo que as amostras foram tituladas com solução padrão de hidróxido de sódio $0,1 \mathrm{M}$, utilizandose o indicador fenolftaleína. Os resultados foram expressos em porcentagem de ácido cítrico, visto que é o ácido predominante na graviola (BRASIL, 2008).

Quanto à composição nutricional e valor energético foram realizadas as determinações de umidade e cinzas na polpa de graviola; no resíduo a umidade foi realizada por método de secagem em estufa e cinzas, por método de incineração em muflla a $550^{\circ} \mathrm{C}$, ambas conforme metodologia do Instituto Adolfo Lutz (BRASIL/IAL, 2008). As análises foram realizadas em triplicata. Para o cálculo da informação nutricional (lipídeos, proteínas, carboidratos) dos muffins, foram utilizadas as orientações da Anvisa (Brasil, 2005), utilizando as informações contidas nas embalagens dos ingredientes e a Tabela de Composição dos Alimentos (NEPA/UNICAMP, 2011). O valor energético foi calculado utilizando os seguintes fatores de conversão: para proteína e carboidratos iguais a $4,0 \mathrm{kcal} \mathrm{g}^{-1}$ e para lipídeo igual a 9,0 $\mathrm{kcal} \mathrm{g}^{-1}$ segundo a RDC $\mathrm{n}^{\circ} 360$, da Agência Nacional de Vigilância Sanitária - ANVISA (BRASIL, 2003).

Para caracterização física dos muffins foram avaliados: peso, espessura, diâmetro e uniformidade da crosta. A pesagem foi feita em balança de precisão (marca e modelo citados), assim como a espessura e o diâmetro que foram realizados de acordo com o método 10- 50D (AACC, 2000), determinados com o auxílio de paquímetro $150 \mathrm{~mm}$ digital de medição linear. As Figura 4 apresentam a realização da mensuração da espessura e do diâmetro dos muffins.

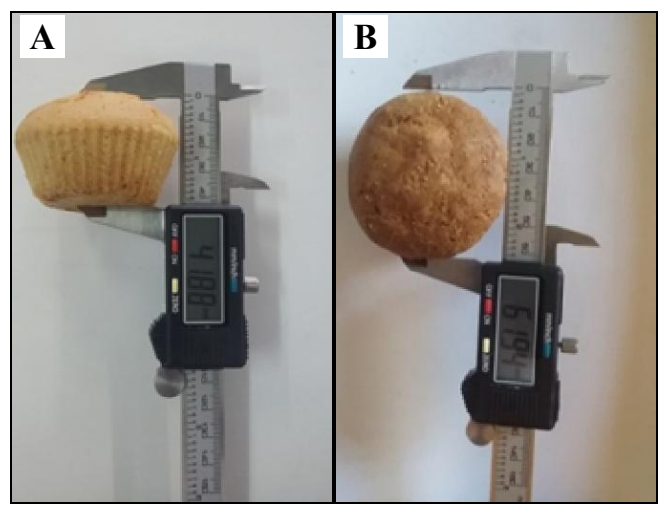

Figura 4. Determinação da espessura (A) e do diâmetro (B) dos muffins.

A pesagem, antes (Figura 5A) e depois do forneamento (Figura 5B), foi realizada em balança de precisão. A pesagem antes foi feita com a massa ainda nas forminhas, sendo que o peso das forminhas foi desconsiderado, depois dos muffins terem atingido a temperatura ambiente, foi feita a pesagem após a desenformagem, (retirada integral do bolinho, deixando quase nenhum resíduo nas forminhas, de modo que redução de massa é insignificante).

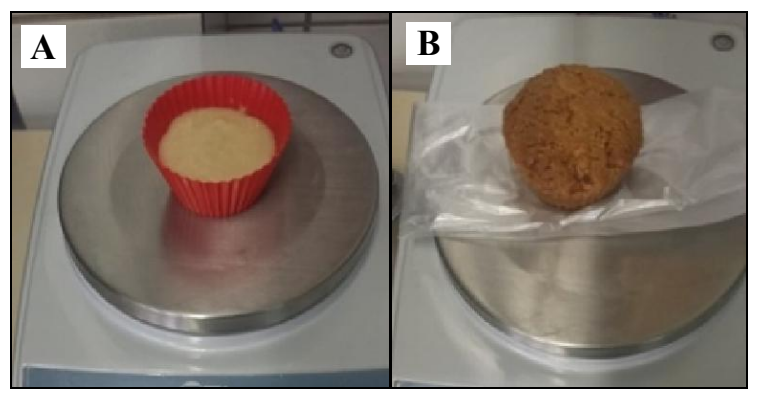

Figura 5. Determinação da massa antes (A) e após (B) o forneamento dos muffins.

Os recipientes (formas) foram preenchidos com a mesma quantidade de massa em todas as formulações, entretanto a pesagem antes do forneamento demonstrou distinções entre os pesos, possivelmente em decorrência da diferença no volume dos ingredientes que tiveram sua proporção alterada em cada formulação. $\mathrm{O}$ tratamento T0 foi estatisticamente igual ao T10, porém se distinguiu de todos os outros tratamentos que foram iguais entre si. A análise das formulações de muffins com 0 \% (padrão sem adição), e com 10, 20 e $30 \%$ de 
adição do resíduo da polpa de graviola se procedeu conforme citado anteriormente na realização das análises para polpa e resíduo (BRASIL/IAL, 2008).

Os dados obtidos foram avaliados em delineamento inteiramente casualizado pelo método de análise de Variância (ANOVA), foi aplicado o teste de Tukey a $5 \%$ probabilidade. Para a análise dos resultados obtidos do cálculo da composição nutricional foi aplicado o teste $t$ a $5 \%$ de probabilidade. A análise estatística foi realizada utilizando programa ASSISTAT de análise estatística experimental (SILVA, 2016).

\section{Resultados e Discussão}

Na Tabela 2 estão os valores obtidos das análises de $\mathrm{pH}$, Acidez titulável, Sólidos Solúveis Totais, umidade e cinzas da polpa e do resíduo da polpa de graviola. A temperatura média das medições foi de $29,54 \pm 0,15^{\circ} \mathrm{C}$.

Os valores obtidos de $\mathrm{pH}$ para a polpa, encontram-se dentro dos Padrões de Identidade e Qualidade (PIQ) estabelecidos pelo Ministério da Agricultura (BRASIL, 1999), para polpa de graviola, sendo que a mesma deve apresentar $\mathrm{pH} \geq 3,50$. Houve diferença estatística significativa entre a polpa de graviola e o resíduo, pois possivelmente a filtragem extrai alguns compostos, entre eles, os ácidos, principalmente o ácido cítrico, que se encontram em menor proporção no resíduo, pois, por se tratar de um resíduo e não do fruto integral, os padrões para a polpa provavelmente não se aplicam da mesma forma, já que para sua obtenção é retirado o suco que possivelmente leva boa parte dos compostos solúveis presentes na polpa, desta forma, pode ter ocorrido perda de ácido cítrico na extração do suco.

Tabela 2. Valores de $\mathrm{pH}$, acidez titulável, SST, umidade e cinzas da polpa e do resíduo da polpa de graviola in natura

\begin{tabular}{ccc}
\hline Determinações & $\mathrm{GP}^{*}$ & $\mathrm{GR}^{*}$ \\
\hline Acidez titulável & $0,91 \pm 0,14^{\mathrm{a}}$ & $0,34 \pm 0,01^{\mathrm{b}}$ \\
$\mathrm{pH}$ & $4,01 \pm 0,04^{\mathrm{a}}$ & $3,81 \pm 0,03^{\mathrm{b}}$ \\
SST & $10,53 \pm 0,35^{\mathrm{a}}$ & $6,40 \pm 0,58^{\mathrm{b}}$ \\
Umidade & $90,55 \pm 0,20^{\mathrm{a}}$ & $86,85 \pm 0,37^{\mathrm{b}}$ \\
Cinzas & $0,41 \pm 0,08^{\mathrm{a}}$ & $0,59 \pm 0,30^{\mathrm{a}}$ \\
\hline
\end{tabular}

*Média obtidas por triplicata \pm Desvio Padrão

GP: Polpa de Graviola; GR: Resíduo de Graviola.

As letras minúsculas diferentes, em uma mesma linha, apresentam diferença estatística entre si pelo teste de Tukey $(p<0,05)$.

O $\mathrm{pH}$ das amostras do resíduo de graviola, encontram-se dentro dos padrões de qualidade mencionados. Leal et al. (2013), em sua análise do pH para polpa de graviola encontrou valor médio de $\mathrm{pH} \geq$ 3,39 , um pouco inferiores aos valores encontrados, o que pode ter ocorrido devido à possíveis diferenças na filtragem podendo ter havido uma menor eliminação de líquidos o que possibilita menor eliminação de ácido cítrico presente no suco proveniente da polpa, podem ter ocorrido também diferenças no tipo de amostragem, diferenças no solo, tipo de irrigação, clima, fatores estes que podem influenciar das características das frutas.

Os resultados encontrados também estão semelhantes aos dados encontrados por Sacramento (2003) que para a polpa de graviola obtiveram valor médio de 3. Em relação à acidez, os valores encontrados tanto para a polpa (GP) quanto para o resíduo da polpa (GR) apresentaram diferença estatística entre si. Para GP os valores obtidos encontram-se dentro dos padrões de identidade e qualidade, Brasil (1999), que estabelece mínimo de 0,60 g/100g para acidez total expressa em ácido cítrico. Ácido predominante na graviola. Os resultados encontrados são semelhantes aos valores encontrado por Sacramento (2003) que analisaram três tipos de graviola, os valores encontrados por estes autores variaram de 0,92 a $1,0 \mathrm{~g} / 100 \mathrm{~g}$. E pelos encontrados por Leal et al. (2013) onde variaram de 0,9 a $1,29 \mathrm{~g} / 100 \mathrm{~g}$.

Já os valores encontrados na análise de acidez do resíduo, obtiveram-se médias bem mais baixas que os padrões citados para polpa de acordo com Brasil (1999), porém não existe um padrão para resíduo, de forma que não é possível estabelecer um padrão pela legislação. Porém, por se tratar de um resíduo e não do fruto integral, os padrões para a polpa provavelmente não se aplicam da mesma forma, já que para sua obtenção é retirado o suco que possivelmente leva boa parte dos compostos presentes na polpa, desta forma, pode ter ocorrido perda dos ácidos na extração do suco.

Para o valor de SST (sólidos solúveis totais) também obteve-se diferença significativa entre as amostras analisadas da polpa do fruto e o resíduo (Tabela 2), verificando-se uma redução no teor de sólidos solúveis no resíduo em relação a polpa. Segundo Sacramento (2003), nos frutos das anonáceas há elevado teor de sólidos solúveis constituídos principalmente de açúcares solúveis. Desta forma, a redução pode-se justificar pela filtragem realizada para a obtenção do resíduo que elimina boa parte do líquido (suco), mais rico em sólidos solúveis e açúcares redutores. Os valores para polpa atendem ao padrão de qualidade que estabelece mínimo de $9,0^{\circ}$ Brix. Todavia, a diferença pode ser justificada por fatores ambientais, como clima, região época do ano e também em decorrência de fatores de cultivo, como o solo, irrigação, tempo para maturação dos frutos, entre outros.

Em relação à umidade também houve diferença estatística significativa entre GP e GR. A Tabela de Composição Nutricional - TACO (NEPA, 2011), define para a polpa de graviola congelada valor de umidade de 89,2 , valor bem próximo ao valor encontrado. $\mathrm{Na}$ TACO (NEPA/UNICAMP, 2011) não constam dados de resíduo de polpa de graviola. São José et al. (1997) 
verificaram valores de 78 a $85,3 \%$ de umidade para $100 \mathrm{~g}$ de polpa, inferiores aos valores de umidade encontrados no presente estudo. De acordo com a Tabela Brasileira de Composição de Alimentos TACO, o valor para umidade da polpa de graviola não congelada é 82,2 , inferior ao valor citado pela tabela para a polpa congelada. Já o valor obtido por esse autor para o resíduo da polpa situa-se bem próximo ao encontrado neste estudo.

Para cinzas não se obteve diferença significativa entre a polpa de graviola e o resíduo. Esse resultado pode ter ocorrido devido à filtragem ou à trituração do resíduo e à possíveis fatores intrínsecos da fruta, como por exemplo a aderência das fibras. A Tabela Brasileira de Composição de Alimentos (NEPA/UNICAMP, 2011) cita como valor encontrado de cinzas em polpa de graviola congelada de $0,4 \mathrm{~g}$ por $100 \mathrm{~g}$, valor praticamente idêntico ao encontrado neste estudo. São José et al. (1997) obtiveram valor de $0,53 \mathrm{~g} / 100 \mathrm{~g}$ de cinzas para a polpa, que foi semelhante ao valor encontrado.

O nível de rompimento da superfície (crosta) dos muffins diminuiu gradualmente à medida que a concentração de resíduo da polpa de graviola aumentava, provavelmente porque o resíduo pode ter apresentado uma propriedade de maior retenção de ar, que quase não ocorreu nas amostras em que não foi adicionado o resíduo. Os muffins com $0 \%$ de adição de resíduo obtiveram o maior rompimento, seguidos pelos com $10 \%$ de adição, sendo que os muffins com 20 e 30\% de adição não apresentaram visualmente grandes diferenças entre si, entretanto em relação às amostras dos outros dois tratamentos ( 0 e $30 \%)$ é possível observar as diferenças na superfície da crosta provavelmente devido à baixa retenção de $\mathrm{CO}_{2}$ durante o forneamento, visto que a farinha de arroz por si não possui grande capacidade de retenção, pois não forma a rede de glúten; dessa forma as fibras do resíduo atuariam possivelmente também como uma espécie de rede auxiliando na expansão e retenção.

Os muffins desenvolvidos submetidos ao mesmo tratamento de tempo e temperatura de forneamento obtiveram características bem definidas e distintas (Figura 6), variando a coloração, uniformidade da superfície, peso, espessura e diâmetro de acordo com as variações no grau de substituição de resíduo por polpa de graviola (Tabela 3). A Figura 6 mostra a crosta (parte superior) das formulações desenvolvidas de acordo com o nível de substituição de farinha de arroz por resíduo.

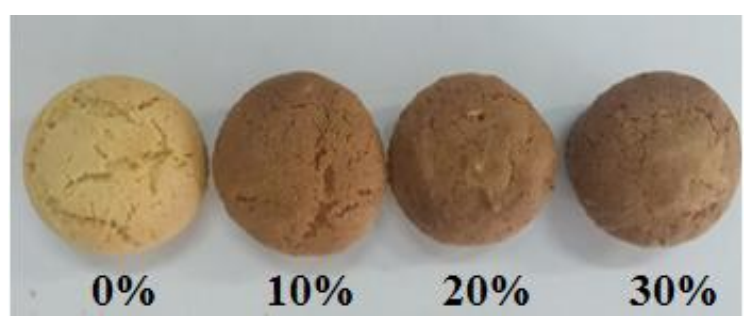

Figura 6. Formulações desenvolvidas, de acordo com os níveis de substituição de farinha de arroz por resíduo de polpa de graviola.

De acordo com a Tabela 3, nota-se que a espessura e o diâmetro também variaram em relação ao aumento na proporção de polpa adicionada. Pode-se dizer então, a partir da observação dos resultados, que o resíduo atuou favorecendo o crescimento e retenção de ar durante o forneamento, não permitindo que a crosta se rompesse, promovendo certa melhoria nas características da massa. Na Tabela 3 estão os resultados obtidos para o diâmetro e peso dos muffins elaborados com e sem resíduo da polpa de graviola.

Em relação à coloração dos muffins houve também um escurecimento da superfície, que aumentou proporcionalmente ao aumento na adição do resíduo obtendo à coloração mais escura nos muffins com $30 \%$ de adição e consequentemente mais clara nos muffins com $0 \%$ de adição de resíduo. O que se pode justificar devido à significativa concentração de açucares redutores na graviola, que provavelmente influenciam na reação de Maillard durante o forneamento.

A Figura 7 apresenta o aspecto do miolo dos muffins desenvolvidos. Na Figura 7A é possível observar o aspecto do miolo de um muffin obtido a partir da formulação com $0 \%$ de adição de resíduo de polpa de graviola. Em comparativo, a Figura 7B demonstra uma formulação com o máximo de adição de resíduo (30\%). É possível constatar observando os dois exemplos, que a coloração do miolo dos muffins em que foi feita a adição do resíduo é um pouco mais escura em relação a formulação em que não foi feita a adição, assim como ocorreu com a crosta.

Tabela 3: Espessura, diâmetro e peso dos muffins elaborados com e sem resíduo da polpa de graviola

\begin{tabular}{|c|c|c|c|c|}
\hline \multirow[t]{2}{*}{ Análises } & \multicolumn{4}{|c|}{ Tratamentos } \\
\hline & T0 & T10 & T20 & T30 \\
\hline Peso antes (g) & $52,90 \pm 0,01^{\mathrm{a}}$ & $52,88 \pm 0,01^{\mathrm{ab}}$ & $52,87 \pm 0,01^{\mathrm{b}}$ & $52,86 \pm 0,01^{b}$ \\
\hline Peso depois ( $\mathrm{g}$ ) & $49,85 \pm 0,03^{\mathrm{a}}$ & $48,99 \pm 0,04^{\mathrm{b}}$ & $48,80 \pm 0,06^{\mathrm{c}}$ & $48,73 \pm 0,04^{\mathrm{c}}$ \\
\hline Espessura depois (cm) & $3,81 \pm 0,06^{\mathrm{c}}$ & $3,90 \pm 0,04^{\mathrm{bc}}$ & $3,97 \pm 0,01^{\mathrm{ab}}$ & $4,01 \pm 0,04^{\mathrm{a}}$ \\
\hline Diâmetro depois (cm) & $5,78 \pm 0,03^{\mathrm{c}}$ & $6,09 \pm 0,02^{b}$ & $6,14 \pm 0,06^{\mathrm{ab}}$ & $6,20 \pm 0,03^{\mathrm{a}}$ \\
\hline
\end{tabular}

As letras minúsculas diferentes em uma mesma linha apresentam diferença estatística entre si pelo teste de Tukey $(p<0,05)$. 


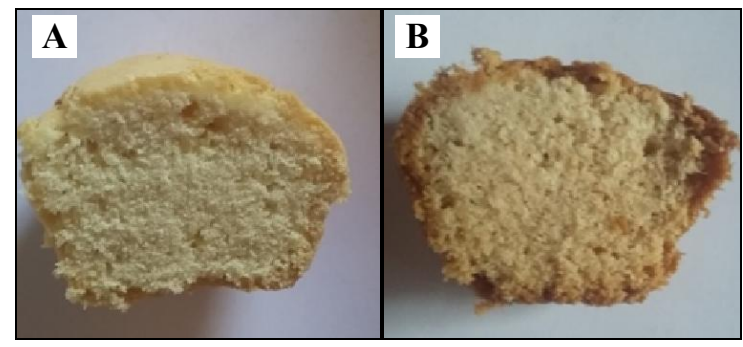

Figura 7. Aspecto do miolo do muffin sem adição do resíduo do resíduo de polpa de graviola (A) e com maior adição de $30 \%$ de resíduo de polpa de graviola (B).

Analisando ainda a Figura 7 é possível observar que a massa sem adição do resíduo, após o forneamento se mostra mais seca, densa e rígida. Também foi possível notar uma melhor aeração e leveza da massa, no muffin que foi feita a substituição parcial pelo resíduo.

Após o forneamento, os muffins perderam um pouco de massa devido à perda de umidade com o aquecimento, como foi possível observar na Tabela 3, sendo que T0 e T20 foram consideradas diferentes estatisticamente ente si e diferentes dos demais tratamentos. Os tratamentos T20 e T30 foram considerados iguais entre si.

Para o diâmetro observou-se entre os tratamentos T30 e T20 não se obteve diferença significativa, assim como entre T20 e T10, o qual foi estatisticamente diferente de $\mathrm{T} 0$ e T30, que também se diferiram entre si.

A análise estatística mostrou que para a espessura, medida após o forneamento, houve diferença significativa entre os tratamentos T0 e T30, porém T20 foi considerado estatisticamente igual à T30 e T10. Não houve diferença significativa entre $\mathrm{T} 10$ e $\mathrm{T} 0$, entretanto T20 apresentou diferença significativa em relação à T0.

Em geral, o diâmetro bem como a espessura aumentou também gradualmente com o aumento na porcentagem de substituição de polpa de resíduo de graviola, comprovando os efeitos benéficos do resíduo sobre as propriedades massa, como crescimento e expansão. Essa propriedade possivelmente está relacionada ao fato de que o resíduo é extremamente fibroso, o que provavelmente atua semelhante à rede de glúten na massa, proporcionando maior retenção de $\mathrm{CO}_{2}$. Contudo, em geral verificou-se visualmente um bom desenvolvimento e crescimento da massa sem glúten, principalmente nas formulações que continham o resíduo, sobretudo nas com maior adição.
Para a porcentagem de expansão do volume da massa foi feito o cálculo pela fórmula: Coeficiente de expansão $=$ (volume da massa - volume da massa crua)/volume da massa crua * 100, conforme metodologia citada por PEREIRA et al. (2010).

Pode-se observar na Tabela 4 que entre as médias do tratamento T0 e T10 não houve diferença significativa, assim como entre T10 e T20 e T20 e 30 . O que pode levar a concluir que tratamentos paralelos não apresentaram diferença significativa. A análise estatística constatou que houve diferença significativa entre os Tratamentos T30 e T0, entre T20 e T0 e entre T10 e T30. É possível observar ainda que a porcentagem de expansão foi proporcional ao aumento na quantidade de resíduo de polpa adicionado, o que indica que o resíduo proporcionou melhorias na expansão da massa. Em seu estudo, Perez e Germani (2007) obtiveram médias de expansão de $51,06,49,62$ e $38,96 \%$, valores relativamente próximos aos encontrados.

Na Tabela 5 estão dispostos os valores encontrados para umidade, cinzas e $\mathrm{pH}$ nas formulações desenvolvidas, e também a composição nutricional. Pelos cálculos o valor energético foi considerado significativamente diferente em todos os tratamentos. Para os lipídeos as médias foram consideradas estatisticamente iguais entre si. Já em relação às proteínas as médias para todos os tratamentos foram consideradas diferentes entre sí.

Para os carboidratos T0 e T10 foram considerados iguais entre si e diferente de T20 e T30, que também se diferiram entre si. Como se pode observar ainda, analisando a Tabela 5, as menores médias de carboidratos e valor energético (T30), são as que tiveram a maior adição de polpa e consequentemente menor adição de farinha de arroz, rica em amido. Desta forma teoricamente haveria boas chances de a adição do resíduo como substituição de parte da farinha poder conferir aos muffins boas propriedades nutricionais e menor valor calórico energético.

$\mathrm{O}$ tratamento $\mathrm{T} 0$ em relação a umidade foi o único que diferiu significativamente do restante dos tratamentos que foram considerados iguais entre si. Provavelmente isso se deu devido ao fato de que esse tratamento foi o único que não possuía a adição do resíduo da polpa o que ocasionou menor umidade da massa.

Tabela 4. Porcentagem de expansão da massa após o forneamento dos muffins

\begin{tabular}{ccccc}
\hline Análise & \multicolumn{4}{c}{ Tratamentos } \\
\cline { 2 - 4 } & $\mathrm{T} 0$ & $\mathrm{~T} 10$ & $\mathrm{~T} 20$ & $\mathrm{~T} 30$ \\
\hline Expansão da massa (\%) & $47,45 \pm 0,76^{\mathrm{c}}$ & $48,72 \pm 0,47^{\mathrm{bc}}$ & $49,58 \pm 0,26^{\text {ab }}$ & $50,12 \pm 0,50^{\mathrm{a}}$ \\
\hline * As letras minúsculas diferentes em uma mesma linha apresentam diferença estatística entre si pelo teste $\mathrm{t}(\mathrm{p}<0,05)$. &
\end{tabular}


Tabela 5: Composição química dos muffins com substituição parcial da farinha de arroz por resíduo da polpa de graviola

\begin{tabular}{|c|c|c|c|c|}
\hline \multirow[t]{2}{*}{ Determinações } & \multicolumn{4}{|c|}{ Tratamentos $(\mathrm{g} / 100 \mathrm{~g})$} \\
\hline & T0 & $\mathrm{T} 10$ & $\mathrm{~T} 20$ & $\mathrm{~T} 30$ \\
\hline *Valor energético (Kcal) & $177,51^{\mathrm{a}}$ & $174,2^{b}$ & $170,88^{\mathrm{c}}$ & $167,56^{\mathrm{d}}$ \\
\hline Lipídeos & $8,1^{\text {a }}$ & $8,08^{a}$ & $8,05^{\mathrm{a}}$ & $8,05^{\mathrm{a}}$ \\
\hline Proteínas & $2,3^{a}$ & $2,27^{\mathrm{b}}$ & $2,17^{\mathrm{c}}$ & $2,07^{\mathrm{d}}$ \\
\hline Carboidratos* & $23,1^{a}$ & $23,10^{\mathrm{a}}$ & $22,9^{b}$ & $21,77^{\mathrm{c}}$ \\
\hline$* *$ Umidade & $11,60^{b}$ & $14,48^{a}$ & $14,82^{\text {a }}$ & $14,90^{\mathrm{a}}$ \\
\hline Cinzas & $2,18^{\mathrm{a}}$ & $2,28^{\mathrm{a}}$ & $2,28^{\mathrm{a}}$ & $2,41^{\mathrm{a}}$ \\
\hline $\mathrm{pH}^{* *}$ & $9.7^{\mathrm{a}}$ & $9.3^{b}$ & $8,5^{\mathrm{c}}$ & $8,0^{\mathrm{d}}$ \\
\hline
\end{tabular}

A adição do resíduo torna a massa mais macia, aerada podendo facilmente obter características satisfatórias que substituiu a adição de leite a massa, obtendo-se um produto com boas características de textura, além de ser totalmente livre de lactose, que conduz intolerância em muitos indivíduos e outros compostos presentes no leite causadores de alergias.

Pode-se observar ainda na Tabela 4 que na análise estatística das médias obtidas para as cinzas, não consta diferença significativa entre as formulações para os níveis de substituição utilizados. Não foram encontrados na literatura dados relativos a umidade e cinzas especificamente para muffins. Mas pode ser explicado pelo valor equivalente encontrado na análise polpa e resíduo. Bitencourt (2014) em avaliação de bolos enriquecidos com semente de abóbora, obteve valores médios de 8,47 à $9,14 \%$ de umidade e 1,06 a 1,49 para cinzas, médias inferiores ao valor encontrados. Já em relação ao $\mathrm{pH}$ o aumento na porcentagem de adição de resíduo de polpa de graviola ocasionou a diminuição do mesmo, provavelmente em decorrência da acidez do resíduo, obtendo diferença significativa entre todos os tratamentos.

Dados de informação nutricional de uma marca de muffin industrializado presente no mercado indica que uma porção $(30 \mathrm{~g})$ possui a seguinte composição nutricional: $105 \mathrm{Kcal}$; 4,1g de carboidratos; 3,3g de lipídeos e 4,2 g de proteínas. Indicando altos níveis de calorias e lipídeos, utilizando a conversão de g/100g (informações presentes no rótulo). Grande parte das formulações de bolos industrializados no mercado, em grande parte destinadas ao público infantil, não são destinadas a indivíduos com restrições alimentares. De modo que dificulta o acesso do público celíaco e dos intolerantes.

\section{Conclusões}

As formulações de muffins produzidos com o resíduo de graviola obtiveram uma maior expansão da massa e menor rompimento da crosta do que na formulação sem a adição de resíduo de polpa de graviola já que muffins com maiores adições de resíduo de graviola apresentaram maiores valores para diâmetro e espessura.
O processo de filtração para obtenção do resíduo elimina muitos componentes da polpa íntegra, como grande parte dos sólidos solúveis e ácidos, visto que as análises demonstraram que a concentração dos mesmos é superior na polpa que no resíduo, entretanto o resíduo mostrou propriedades tecnológicas diferenciadas em relação à coloração e crescimento da massa, demostrando que influencia positivamente nas características de crescimento e expansão, sendo um bom auxiliar na formulação.

Em geral, pode-se considerar como mais satisfatória o tratamento T30 com adição da maior quantidade de resíduo de polpa de graviola, visto que os resultados indicam que este tratamento obteve as melhores valores de diâmetro e espessura, proporcionando consequente melhoria na qualidade de crescimento da massa. Em relação à composição nutricional os muffins apresentaram resultados semelhantes aos apresentados por alguns autores, entretanto quando comparados com muffins, ou produtos semelhantes presentes no mercado, os resultados, encontrados nos cálculos, para o valor calórico, lipídeos e carboidratos apresentou-se ligeiramente diferente, com uma redução do valor calórico e de carboidratos, principalmente nas amostras com maior nível de substituição.

O resíduo pode apresentar características químicas interessantes, principalmente em relação a sua umidade que pode substituir a adição de leite nas formulações, tornando-se um produto isento de lactose e outros compostos do leite. De forma que é perfeitamente possível utilizar o resíduo da polpa de graviola em processos tecnológicos industriais como a panificação e ainda oferecer um produto isento de lactose e glúten.

\section{Referências Bibliográficas}

ABIMAPI. Associação Brasileira das Indústrias de Biscoitos, Massas Alimentícias e Pães e Bolos Industrializados. Estatísticas de Pães e Bolos Industrializados 2015. São Paulo-SP. Disponível em: http://www.abimapi.com.br/estatistica-paesbolos.php. Acesso em 14 de julho de 2016.

AACC. AMERICAN ASSOCIATION OF CEREAL CHEMISTS. Approved Methods of the American Association of Cereal Chemists. 10a . ed. Saint Paul: AACC, 2000. 
BITENCOURT, C. DUTRA, F. L. G. PINTO, V. Z. HELBIG, E. BORGES, L. R. Elaboração de bolos enriquecidos com semente de abóbora: avaliação química, física e sensorial. B.CEPPA, Curitiba-PR, v. 32, n. 1, p. 19-32, 2014.

BRASIL/IAL. INSTITUTO ADOLFO LUTZ. Métodos físicoquímicos para analise de alimentos. $4^{\mathrm{a}}$. ed. São Paulo- SP: Instituto Adolfo Lutz, 2008.

BRASIL/ANVISA. Rotulagem nutricional obrigatória: manual de orientação às indústrias de alimentos - $2^{\circ}$ versão/ Agência Nacional de Vigilância Sanitária - Universidade de Brasília Brasília: Ministério da Saúde, Agência Nacional de Vigilância Sanitária/ Universidade de Brasília, 2005. 44 p.

BRASIL/MAPA. MINISTÉRIO DA AGRICULTURA E DO ABASTECIMENTO. Portaria $\mathrm{n}^{\circ}$ 136, de 31 de março de 1999, Diário Oficial [da República Federativa do Brasil], Brasília, DF, $n^{\circ} 62,1^{\circ}$ de abril de 1999, Seção 1. p.25.

BRASIL. Agência Nacional de Vigilância Sanitária. Resolução RDC $\mathrm{n}^{\circ} 360$, de 23 de dezembro de 2003. Aprova regulamento técnico sobre rotulagem nutricional de alimentos embalados, tornando obrigatória a rotulagem nutricional. Diário Oficial [da República Federativa do Brasil], Brasília, DF, 26 de dezembro de 2003.

BORGES A. M. SILVA JÚNIOR, J. P. A. LUCENA, E. M. P. SALES J. C. Estabilidade da pré-mistura de bolo elaborada com $60 \%$ de farinha de banana verde. Ciências Agrotécnicas, LavrasMG, v. 34, n. 1, p. 173-181, 2010.

CÉSAR. A. S., GOMES, J. C., CRISTINA, D. S., FANNI, M. L. BORGES, M. C. Elaboração de Pão Sem Glúten. Revista Ceres, Viçosa-MG, v. 53, n. 306, p.150-155, 2006.

GARIB, T. M., GASQUES, J.G., BASTOS, E. T., TUBINO, M. A. A., SOUZA, G. S. GOMES, E. G. Projeções do Agronegócio Brasil 2014/15 a 2024/25. Projeções de Longo Prazo. Ministério da Agricultura, Pecuária e Abastecimento-MAPA. Brasília-DF, 2015 Disponível http://www.agricultura.gov.br/arq_editor/PROJECOES_DO_AG RONEGOCIO 2025 WEB.pdf. Acesso em: 27 fev. 2016.

LEAL, R. C.; REIS, V. B.; LUZ, D. A. Avaliação de parâmetros fisico-químico de polpas congeladas de graviola comercializada em supermercados de São Luís-MA. Cadernos de Pesquisa, São Luís-MA, v. 20, n. 2, 2013.

LÓPEZ, A. C. B.; PEREIRA, A. J. G..; JUNQUEIRA, R. G. Flour mixture of rice flour, corn and cassava starch in the production of gluten-free white bread. Brazilian. Archivos Biological Technology, Curitiba-PR, v.47, n. 1, p. 63-70, 2004.

MARTÍNEZ-CERVERA, S.; SANZ, T.; SALVADOR, A.; FISZMAN, S.M. Rheological, textural and sensorial properties of low-sucrose muffins reformulated with sucralose/polydextrose. LWT - Food Science and Technology, v. 45, n. 2, p. 213-220, 2012.

MATTAR, R.; MAZO, D. F. C. Intolerância à Lactose: Mudança de Paradigmas com a Biologia Molecular. Departamento de Gastroenterologia da Faculdade de Medicina da Universidade de São Paulo. Revista da Associação Médica Brasileira, São PauloSP, v. 56, n. 2, p. 230-236, 2010.

MAURÍCIO, A. A. BUCHARLES, P. B. BOLINI, H. M. A. SOUSA, V. M.C. Bolo de cenoura com e sem glúten: desenvolvimento da formulação e aceitação do produto. Centro de Ciências Agrárias - Universidade Federal de Roraima. Revista Agro Ambiente, Boa Vista-RO, v. 6, n. 3, p. 250-257, 2012.
NEPA/UNICAMP. NÚCLEO DE ESTUDOS E PESQUISAS EM ALIMENTAÇÃO. Universidade Estadual de Campinas [NEPA/Unicamp]. Tabela Brasileira de Composição de Alimentos [TACO]: versão 1. São Paulo-SP: NEPA/Unicamp, 2011.

OLIVEIRA, M. A. S. (Ed.). Graviola: Produção, Aspectos Técnicos. Empresa Brasileira de Pesquisa Agropecuária. Embrapa Cerrados. Ministério da Agricultura Pecuária e Abastecimento. Brasília-DF: Embrapa - Informação Tecnológica, 2001. 78 p.

PEREIRA, A. C. S.; MOURA, S. M.; CONSTANT, P. B. L. Alergia alimentar: sistema imunológico e principais alimentos envolvidos Semina: Ciências Biológicas e da Saúde, LondrinaPR, v. 29, n. 2, p. 189-200, 2008.

PEREIRA, P. A. P.; RAMOS, T. M.; GAJO, A. A.; GOMES, U. J. Viabilidade da utilização de queijo tipo ricota na elaboração de pão de queijo. Ciência Rural, Santa Maria-RS, v. 40, n. 11, p. 2356-2360, 2010.

PEREZ, P. M. P. GERMANI, R. Elaboração de biscoitos tipo salgado, com alto teor de fibra alimentar, utilizando farinha de berinjela (Solanum melongena, L.). Ciência e Tecnologia de Alimentos, Campinas-SP, v. 27, n. 1, p. 186-192, 2007.

REETZ, E. R. Anuário Brasileiro da Fruticultura. Santa Cruz do Sul-RS: Editora Gazeta, 2015. 104 p.

SACRAMENTO, C. K. Caracterização Física e Química de Frutos de Três Tipos de Gravioleira (Annona muricata L.). Revista Brasileira de Fruticultura, Jaboticabal-SP, v. 25, n. 2, p. 329-331, 2003.

SANTOS, D. C. MOREIRA, A. S. OLIVEIRA, E. N. A. SANTOS, Y. M. G. Elaboração de bebida tipo néctar de graviola adoçada com mel de Apis melifera. Revista Caatinga, MossoróRN, v. 27, n. 4 , p. $216-225,2014$

SÃO JOSÉ, A. R.; SOUZA, I. V. B.; MORAIS, O. M.; REBOUÇAS, T. N. Anonáceas, produção e mercado (Pinha, Graviola, Atemóia e Cherimólia). Vitória da Conquista-BA: UESB -. Departamento de Fitotecnia e Zootecnia, 1997. 312 p.

SÃO JOSÉ, A. R.; PIRES, M. M.; FREITAS, A. L. G. E.; RIBEIRO, D. P.; PREREZ, L. A. A. Atualidades e perspectivas das Anonáceas no mundo. Revista Brasileira de Fruticultura, Jaboticabal-SP, v. 36, n. esp, p. 86-93, 2014.

SILVA, F.A.S. ASSISTAT: Versão 7.7 beta. DEAG-CTRNUFCG. Atualizado em 04 de janeiro de 2016. Disponível em: http://www.assistat.com/indexp.html. Acesso em: 20 de fevereiro de 2016.

SOLÉ, D. SILVA, L. R. FILHO, N. A. SARNI, R. R. O. S. Consenso Brasileiro sobre Alergia Alimentar: 2007. Revista Brasileira de Alergia e Imunopatologia, Minas Gerais-MG, vol. 31, n. 2, p. 64-89, 2008

LIMA, A.; VIEIRA, L. M.; SILVA, M. J. M.; SOUSA, S. B. Caracterização nutricional e compostos antioxidantes em resíduos de polpas de frutas tropicais. Ciências Agrotécnicas. Lavras-MG, v. 35 , n. 3, p. 554-559, 2011.

TÉO, C. R. P. A. Intolerância à lactose: uma breve revisão para o cuidado nutricional. Arquivo de Ciências da Saúde - Unipar, São José do Rio Preto-SP, v. 6, n. 3, p. 135-140, set./dez. 2002. 